\title{
CONTROLE DE CUPINS EM PLANTIOS DE EUCALIPTO NA REGIÃO CENTRO NORTE DE MINAS GERAIS
}

\author{
Ivan da Costa Ilhéu Fontan ${ }^{1}$ \\ Marlon Michel Antônio Moreira Neto ${ }^{2}$ \\ Sharlles Christian Moreira Dias ${ }^{3}$
}

Resumo: O objetivo do presente estudo foi avaliar em condições de campo a eficiência de princípios ativos alternativos ao fipronil no tratamento de mudas de eucalipto contra o forrageamento por cupins subterrâneos, de modo a subsidiar sua substituição por produtos menos tóxicos ao homem e ao ambiente. O estudo foi conduzido em uma área de implantação de floresta clonal de Eucalyptus urophylla localizada em Curvelo/MG. Foram utilizados os inseticidas fipronil $(800 \mathrm{~g} / \mathrm{Kg})$, imidacloprido $(700 \mathrm{~g} / \mathrm{Kg})$ e tiametoxam $(250 \mathrm{~g} / \mathrm{Kg})$, além de um tratamento testemunha (sem cupinicida). O experimento foi estabelecido em um delineamento em blocos casualizados (DBC) com 5 (cinco) repetições, sendo avaliado o incremento em diâmetro do coleto e altura total, e a biomassa das plantas após 120 dias do plantio. Os produtos cupinicidas utilizados no tratamento por imersão dos substratos não expressaram diferenças significativas $(p<0,05)$ no crescimento das plantas até 120 dias após o plantio no campo, indicando ser possível substituir o produto fipronil por outros registrados para a mesma finalidade e disponíveis no mercado brasileiro.

Palavras-chave: Cupinicida; Eucalipto; Certificação florestal; Cupim.

\footnotetext{
${ }^{1}$ Instituto Federal do Espírito Santo - Campus Ibatiba, Brasil. E-mail: ivanfontan.florestal@gmail.com.

2 Plantar-P\&D, Brasil. E-mail: marlon-moreira@hotmail.com.

${ }^{3}$ Plantar - P\&D, Brasil. E-mail: sharlles.dias@gmail.com.
} 